\title{
Plasma levels of carcinoembryonic antigen in bronchial carcinoma and chronic bronchitis
}

\author{
R. PAUWELS and M. VA N DER STRAETEN \\ Department of Chest Diseases, Academic Hospital, State University, Ghent, Belgium
}

\begin{abstract}
Pauwels, R. and van der Straeten, M. (1975). Thorax, 30, 560-562. Plasma levels of carcinoembryonic antigen in bronchial carcinoma and chronic bronchitis. The plasma levels of carcinoembryonic antigen were increased in $80 \%$ of 49 patients with bronchial carcinoma and in $68 \%$ of 25 patients with an acute exacerbation of chronic bronchitis.

There was no statistically significant difference between the two groups. A single determination of the plasma carcinoembryonic antigen level has no prognostic value in patients with bronchial carcinoma.
\end{abstract}

Carcinoembryonic antigen (CEA) was first described by Gold and Freedman in 1965 (Gold and Freedman, 1965a; Gold and Freedman, 1965b; Gold and Freedman, 1965c). Originally it was thought to be an antigen specific for colonic carcinoma. Subsequently this antigen has been discovered in other gastrointestinal tumours, breast tumours, and bronchial carcinomas.

It appears also to be present at a very low level in normal tissue. The development of a radioimmunoassay method by Thomson and co-workers (Thomson et al., 1969) and the subsequent modifications of this method made it possible to detect CEA in plasma (Chu, Reynoso, and Hansen, 1972). Normal persons rarely exceed a plasma level of $2.5 \mathrm{ng} / \mathrm{ml}$, as measured by the method of Hansen (Hansen, Lance, and Krupey, 1971; Hansen et al., 1974). Raised levels of CEA have been detected in various malignant diseases (Gerfo, Krupey, and Hansen, 1971; Chu and Reynoso, 1972; Laurence et al., 1972; Reynoso et al., 1972; Concannon, Dalbow, and Frich, 1973; Hansen et al., 1974; Terry et al., 1974) but also in nonmalignant inflammatory conditions and in healthy smokers (Hansen et al., 1971; Stevens and Mackay, 1973; Terry et al., 1974).

Our study was started in order to determine the clinical value of plasma CEA levels in bronchial carcinoma and to see if we could in this way discriminate between patients with bronchial carcinoma and patients with other pulmonary disorders. Since most of the patients with bronchial carcinoma also had clinical evidence of chronic bronchitis it was logical to compare them to a group of patients with chronic bronchitis Furthermore, we decided to determine the CE\& level in patients with chronic bronchitis during a acute infectious exacerbation since inflammation seems to be an important stimulus for CEA liberao tion in the blood or CEA production by tissue.

We also tried to correlate the initial $\mathrm{CE} \overrightarrow{\overline{\mathrm{A}}}$ level to survival rate in patients with bronchial carcinoma.

\section{MATERIAL AND METHODS}

CEA levels were determined in the plasma of 49 patients with histologically proven bronchial ca cinoma and in 25 patients with an acute infective. exacerbation of chronic bronchitis. Follow-ư studies were carried out as far as possible. The CEA level was determined by the zirconium ge radio immunoassay method of Hansen et ab (1971), and this was done at the medical research department of Hoffman La Roche, Basel.

Statistical analysis was performed using the Wilcoxon test and calculation of linear correlation

\section{RESULTS}

The CEA plasma levels in the two groups are shown in Figure 1.

Accepting $2.5 \mathrm{ng} / \mathrm{ml}$ as the upper limit of not:mal (Hansen et al., 1974) we found an increase of plasma CEA level in $80 \%$ of the patients with bronchial carcinoma and in $68 \%$ of the patien with an acute exacerbation of chronic bronchitis. There was no statistically significant differenee between the two groups although some very high 


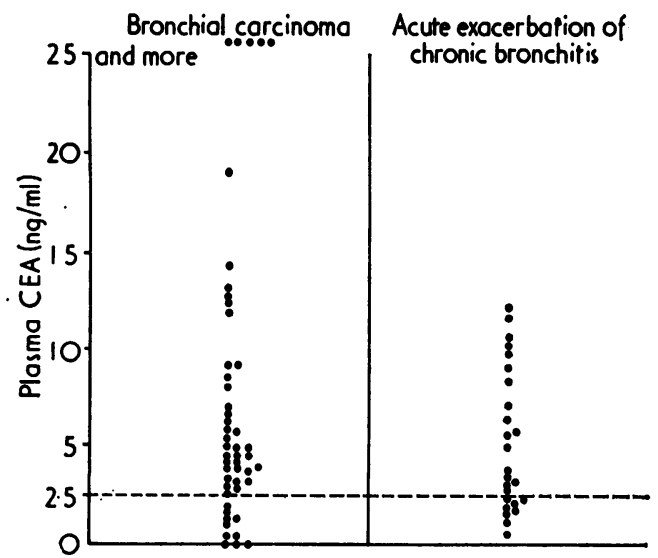

FIG. 1. Plasma CEA levels in patients with bronchial carcinoma (left column) and in patients with an acute exacerbation of chronic bronchitis (right column).

values were found among the carcinoma patients.

When the patients with chronic bronchitis were tested again one to two weeks after the first determination, after the acute exacerbation had responded to treatment with antibiotics, sympathomimetics, methylxanthines, and corticosteroids, no significant lowering of the CEA level was observed (Fig. 2).

Sixteen of the carcinoma patients proved to be operable and subsequently 14 of them underwent lobectomy or pneumonectomy. The other 35 patients received only symptomatic treatment. No chemotherapy was given.

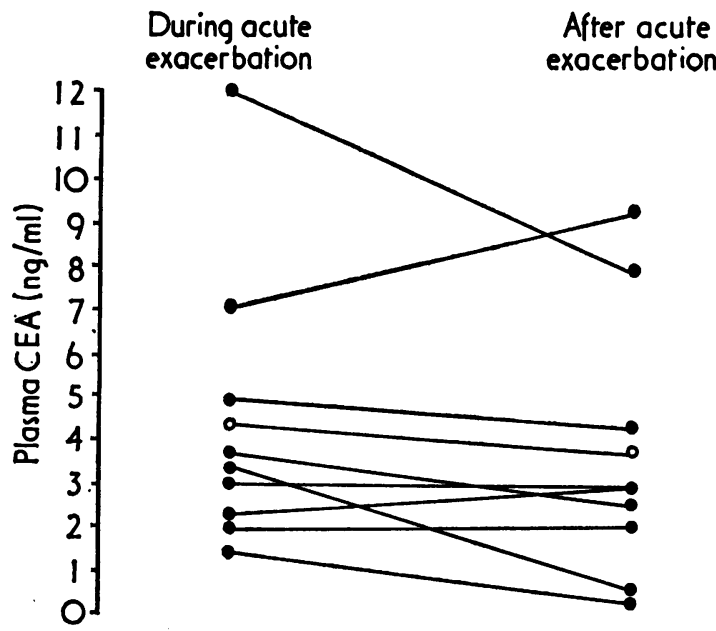

FIG. 2. Plasma CEA levels during and after treatment of an acute exacerbation of chronic bronchitis.
Follow-up of patients with bronchial carcinoma was continued over a period of one year; during this time $70 \%$ of these patients died. When comparing the initial CEA level of patients who died during this year with the level in patients who survived, no statistically significant difference could be found and patients who proved to be operable did not have different CEA levels from the other carcinoma patients (Fig. 3). Moreover, there was no significant correlation between the initial CEA level and the survival time in patients who died (Fig. 4).

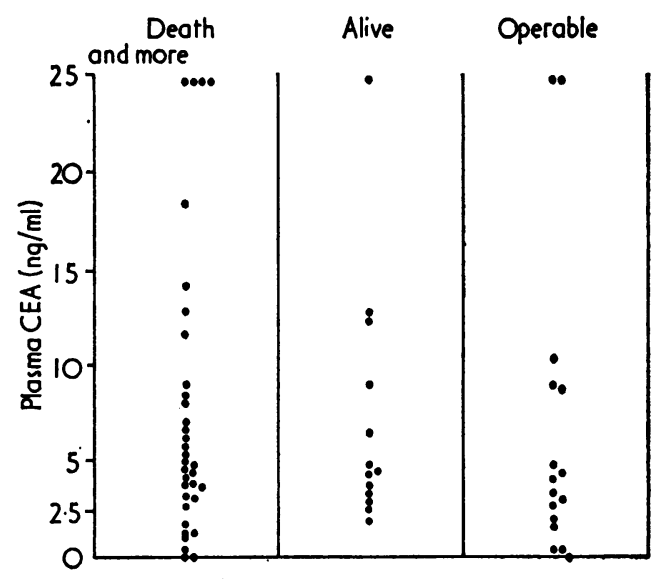

FIG. 3. Initial plasma CEA levels in patients with bronchial carcinoma divided into three groups: those who died within one year, those who survived one year, and those who were operable.

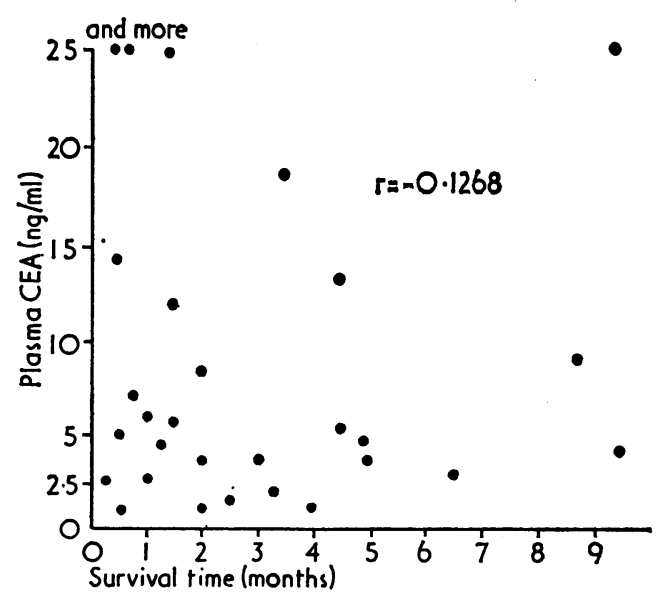

FIG. 4. Correlation between initial plasma CEA level and survival time in the patients with bronchial car. cinoma who died. 


\section{DISCUSSION}

Raised CEA levels have previously been reported in $76 \%$ of patients with pulmonary carcinoma, in $67 \%$ of patients with pulmonary emphysema, in $33 \%$ of patients with bronchitis, in $46 \%$ of patients with pneumonia, and in $37 \%$ of patients with tuberculosis (Hansen et al., 1974). Other studies reported similar findings (Vincent and Chu, 1973; Terry et al., 1974). CEA has also been found in bronchial carcinoma tissue and even in normal lung tissue at a very low concentration (Pusztaszeri and Mach, 1973; Sizaret and Martin, 1973). Our work confirms the high percentage of elevated CEA levels in patients with bronchial carcinoma but CEA appears to be raised to a similar degree during an acute exacerbation of chronic bronchitis. Since patients with bronchial carcinoma often have chronic bronchitis and may also present with an acute pulmonary infection, there is doubt about the clinical value of a single CEA determination in the diagnosis of bronchial carcinoma.

Prognostic studies following CEA measurements in bronchial carcinoma have not previously been reported, and it would seem from our work that little can be expected from a single CEA determination. It is possible that repeated measurements of CEA levels during follow-up and treatment would have more prognostic significance.

\section{REFERENCES}

Chu, T. M. and Reynoso, G. (1972). Evaluation of a new radioimmunoassay method for carcinoembryonic antigen in plasma, with use of zirconyl phosphate gel. Clinical Chemistry, 18, 918.

$\longrightarrow,-$ and Hansen, H. J. (1972). Demonstration of carcinoembryonic antigen in normal human plasma. Nature, 238, 152.

Concannon, J. P., Dalbow, M. H., and Frich, J. C. (1973). Carcinoembryonic antigen (CEA) plasma levels in untreated cancer patients and patients with metastastic disease. Radiology, 108, 191.

Gerfo, P. L., Krupey, J., and Hansen, H. J. (1971). Demonstration of an antigen common to several varieties of neoplasia. Assay using zirconyl phosphate gel. New England Journal of Medicine, 285, 138 .

Gold, P. and Freedman, S. O. (1965a). Demonstration of tumour-specific antigens in human colonic carcinomata by immunological tolerance and absorption techniques. Journal of Experimental Medicine, 121, 439. $\longrightarrow$ and - (1965b). Specific antigen similarity be $\bar{\partial}$ tween malignant adult and normal fetal tissues. of the human digestive system (abstract). Journas of Clinical Investigation, 44, 1051.

and - (1965c). Specific carcino-embryonia antigens of the human digestive system. Journat of Experimental Medicine, 122, 467.

Hansen, H. J., Lance, K. P., and Krupey, J. (1971). Demonstration of an ion sensitive antigen sitê on carcino-embryonic antigen using zircony phosphate gel. Clinical Research, 19, 143.

, Snyder, J. J., Miller, E., Vandevoorde, J. P.屯 Miller, O. N., Hines L. R. and Burns J. J. (1974) Carcinoembryonic antigen (CEA) assay. A laboraio tory adjunct in the diagnosis and managemeng of cancer. Human Pathology, 5, 139.

Laurence, D. J. R., Stevens, U., Bettelheim, R.) Darcy, D., Leese, C., Turberville, C., Alexander. P., Johns, E. W., and Neville, A. M. (1972) Role of plasma carcinoembryonic antigen in diagnosis of gastrointestinal, mammary, an bronchial carcinoma. British Medical Journal, 3, 605.

Pusztaszeri, G. and Mach, J. P. (1973). Carcinoem bryonic antigen (CEA) in non digestive can:cerous and normal tissues. Immunochemistry 10, 197.

Reynoso, G., Chu, T. M., Holyoke, D., Cohen, E. Nemoto, T., Wang, J. J., Chuang, J., Guinanơ P., and Murphy, J. P. (1972). Carcinoembryonia antigen in patients with different cancers. Journal of the American Medical Association, 220, 361 $\vec{F}$

Sizaret, P. and Martin, F. (1973). Carcinoembryonie antigen in extracts of pulmonary cancers. Journap of the National Cancer Institute, 50, 807.

Stevens, D. P. and Mackay, I. R. (1973). Increase carcinoembryonic antigen in heavy cigarette smokers. Lancet, 2, 1238.

Terry, W. D., Henkart, P. A., Coligan, J. E., and Todd, C. W. (1974). Carcinoembryonic antigen: characterization and clinical applications. Trans? plantation Reviews, 20, 100.

Thomson, D. M. P., Krupey, J., Freedman, S. O., and Gold, P. (1969). The radioimmunoassay of cirs culating carcinoembryonic antigen of the human digestive system. Proceedings of the Nationat Academy of Science of the United States of America, 64, 161.

Vincent, R. G. and Chu, T. M. (1973). Carcinoem bryonic antigen in patients with carcinoma of the lung. Journal of Thoracic and Cardiovasculact Surgery, 66, 320.

Requests for reprints to: Dr. R. Pauwels, Departmen@ of Chest Diseases, Academic Hospital, State Univer sity, Ghent, Belgium. 